\title{
Embarkasi dan Debarkasi Penumpang Kapal KM. GUNUNG DEMPO
}

\author{
Rahmaningtyas, $T^{\mathrm{a}}$, Antoro, $\mathbf{D}^{\mathrm{b}}$, Amrullah, R.A ${ }^{\mathrm{c}}$ \\ a,b,c Politeknik Ilmu Pelayaran Semarang \\ ${ }^{a}$ Email: tatarahma07@gmail.com \\ ${ }^{b}$ Email : dwi_antoro@pip-semarang.ac.id \\ ${ }^{c}$ Email : romanda@pip-semarang.ac.id
}

\begin{abstract}
ABSTRAK
Penelitian ini bertujuan untuk mengetahui faktor apa saja yang dapat menyebabkan terjadinya keterlambatan kapal, dan cara mengurangi keterlambatan. Jenis pengamatan yang digunakan adalah deskriptif kualitatif. Pengamatan ini mengambil lokasi di Pelabuhan Anging Mamiri Makassar. Sumber data diperoleh dari narasumber (informan), peristiwa atau aktifitas, dokumen dan arsip. Hasil penelitian menunjukkan bahwa penyebab terjadinya keterlambatan keberangkatan kapal antara lain dapat berupa faktor cuaca yang tidak menentu, tidak tertibnya pengantar, pengunjung, pedagang asongan dan buruh-buruh bagasi pada proses embarkasi dan debarkasi penumpang, serta terjadinya kerusakan mesin. Upaya yang dilakukan untuk mengurangi keterlambatan adalah melakukan pemeriksaan rutin terhadap mesin kapal, selalu menanyakan dan mengecek keadaan cuaca di pelabuhan sandar berikutnya, serta tidak memperbolehkan pengantar, pengunjung, pedagang asongan dan buruh-buruh bagasi untuk naik ke atas kapal.
\end{abstract}

Kata kunci : embarkasi, debarkasi, penumpang.

\section{ABSTRACT}

This study aims to determine what factors can cause ship delays, and how to reduce the delays. The type of observation used is descriptive qualitative. This observation takes place at the Port of Anging Mamiri Makassar. Sources of data obtained from sources (informants), events or activities, documents and archives. The results showed that the cause of the delay in ship departure could be in the form of erratic weather factors, disorderly delivery, visitors, hawkers and baggage workers in the embarkation and debarkation of passengers, as well as engine damage. Efforts made to reduce delays are to always carry out routine checks on ship engines, always inquire and check the weather conditions at the next port port, and do not allow deliveries, visitors, hawkers and baggage workers to get on board.

Keywords: embarkation, debarkation, passenger ship

\section{PENDAHULUAN}

Untuk meningkatkan efisiensi atau melayani keperluan yang lebih luas, kenyamanan dan kemewahan, kadang diperlukan demi memuaskan para penumpang. Lain dari itu kapal penumpang harus memiliki kemampuan bertahan hidup pada situasi darurat (Depdiknas : 2003). Pelayanan di terminal penumpang juga perlu mendapat perhatian dari operator agar penumpang merasakan kepuasan atas https://doi.org/10.46484/db.v1i1.178 pelayanan yang diberikan. Terminal penumpang kapal adalah komponen utama sub sistem pelabuhan yang berfungsi mewadahi aktivitas proses perpindahan penumpang dari satu sistem angkutan laut (kapal penumpang) ke sarana angkutan lain atau sebaliknya (Marlok, 1991; Haronjeff, 1993; Andiani, 2011).

Komponen terminal penumpang antara lain terdiri dari area dermaga, area pelayanan umum, dimensi dermaga, 
fasilitas dermaga, dan bangunan terminal (Andiani : 2011). Banyak aktivitas yang terjadi di terminal penumpang sebagai titik tempat dimana terjadinya perpindahan moda transportasi, dan juga daerah transisi antara darat dan laut. Aktivitas yang terjadi pada terminal penumpang, meliputi aktivitas dermaga, aktivitas derbarkasi, aktivitas embarkasi, aktivitas transit, aktivitas pengantar/penjemput, aktivitas lembaga pelayanan dan pengelolaan penumpang, aktivitas komersial, dan aktivitas transportasi darat. Untuk menjalani fungsinya dan mewadahi segala aktivitas yang ada di dalamnya, maka area terminal dilengkapi fasilitas utama, dan fasilitas penunjang. Fasilitas utama meliputi fasilitas pada zona pertemuan laut, fasilitas pada zona proses, dan fasilitas pada zona pertemuan darat. Fasilitas penunjang dapat berupa fasilitas komersial, fasilitas perkantoran maupun fasilitas rekreasi. Sistem distribusi yang digunakan dalam terminal mempengaruhi kecepatan distribusi penumpang yang akhirnya mempengaruhi kelancaran proses perpindahan moda dalam terminal. Sistem distribusi terdiri dari sistem distribusi horizontal, dan sistem distribusi vertikal (Wijoyono : 2012).

Tujuan dari penelitian adalah untuk mengetahui penyebab terjadinya keterlambatan keberangkatan kapal KM. Gunung Dempo dan untuk mengetahui upaya-upaya apa saja yang dilakukan untuk mengurangi terjadinya keterlambatan pemberangkatan kapal KM. Gunung Dempo.

Arus penumpang atau dengan kata lain embarkasi dan debarkasi ialah pemberangkatan dan penurunan penumpang dengan kapal laut yang dilakukan dari tempat-tempat yang sudah di tetapkan sampai dengan tempat tujuannya (W.J.S Poerwardaminta : 1993).

Embarkasi dan derbarkasi itu mempunyai beberapa keadaan dan situasi dalam keadaan normal seperti pada hari-hari biasa dan situasi yang https://doi.org/10.46484/db.v1i1.178 paling banyak peminatnya. Salah satu contoh adalah pada waktu lebaran dan liburan sekolah, banyak masyarakat yang berpergian keluar pulau. Karena banyaknya peminat tersebutlah sehingga dapat mempengaruhi jadwal keberangkatan penumpang pada umumnya.

Keterlambatan jadwal kapal adalah salah satu permasalahan yang sering dialami oleh KM. Gunung Dempo didalam kegiatan pelayaran kapal laut. Kerugian yang ditimbulkan dari risiko ini pun meliputi kerugian finansial yang cukup besar.

Penyebab keterlambatan KM. Gunung Dempo diantaranya adalah proses embarkasi dan debarkasi kapal yang sering tidak sesuai jadwal sehingga mengakibatkan keterlambatan kapal bertolak dari pelabuhan, sehingga kapal tiba di pelabuhan berikutnya juga mengalami keterlambatan, hal ini tentu mengakibatkan ketidaknyamanan penumpang.

Masalah lain yang sering menghambat adalah pengantar pengunjung dan buruh yang sering membuat kegaduhan di tangga penumpang naik dan turun, sehingga menghambat proses pengecekan tiket dari petugas dan mengakibatkan proses sweeping tiket tidak berjalan opitimal.

Salah satu tugas dan tanggung jawab dari perusahaan pelayaran adalah menjamin keamanan dan keselamatan kapal beserta penumpang dan muatannya. Oleh karena itu, sebelum kapal dioperasikan diperlukan pengujian keselamatan dan keamanan berlayar sesuai ketentuan yang berlaku. Sampai saat ini, kenyamanan dan keamanan di atas kapal penumpang menjadi masalah karena fasilitas dan pelayanan yang kurang baik terutama dirasakan oleh penumpang kelas ekonomi.

Proses embarkasi dan debarkasi merupakan kegiatan yang tidak dapat dipisahkan dari dunia pelayaran. Dalam perkembanganya proses embarkasi dan debarkasi mengalami berbagai permasalahan yang berdampak pada 
jadwal keberangkatan kapal yang tertunda, berdasarkan keadaan yang ada di lapangan. Saat ini proses embarkasi dan debarkasi mengalami banyak permasalahan yang diakibatkan dari pihak kapal sendiri maupun dari pihak luar. Adapun pengaruh dari kapal sendiri seperti tidak tertibnya anak buah kapal terhadap peraturan yang sudah ditetapkan perusahaan mengenai tangga gangway. Sementara pengaruh dari luar meliputi penumpang yang sulit diatur, pengantar dan pengunjung, buruh bagasi.

Berdasarkan keadaan yang ada dilapangan tersebut mencoba dirumuskan tindakan yang harus dilakukan untuk mengatasi keadaan tersebut sehingga permasalahan yang terjadi saat proses embarkasi dan debarkasi dapat dikurangi atau dihilangkan. Permasalahan yang didapat dalam penelitian ini mengenai keterlambatan keberangkatan kapal KM. Gunung Dempo dan upaya-upaya yang dilakukan untuk meminimalisir terjadinya keterlambatan keberangkatan kapal KM. Gunung Dempo.

\section{METODE}

Metode pengumpulan data dipergunakan dalam penulisan ini adalah dengan metode wawancara. Penggunaan metode ini didasarkan pada dua alasan yaitu dengan wawancara peneliti dapat menggali tidak saja apa yang diketahui dan dialami subjek yang diteliti tetapi apa yang tersembunyi jauh di dalam diri subjek penilitian, dan apa yang ditanyakan kepada informan bisa mencakup hal-hal yang bersifat lintas waktu, yang berkaitan dengan masa lampau, masa kini, dan juga masa mendatang. Wawancara yang digunakan adalah wawancara kualitatif. Artinya, dengan mengajukan pertanyaanpertanyaan secara lebih bebas dan leluasa tanpa terkait oleh suatu susunan pertanyaan yang telah dipersiapkan sebelumnya.

Penelitian ini dilakukan di Pelabuhan Anging Mamiri Makassar https://doi.org/10.46484/db.v1i1.178 pada tanggal 20 Mei 2018. Adapun nama kapal dan nama perusahaan yaitu:

$\begin{array}{ll}\text { Nama Kapal } & \text { KM. Gunung } \\ & \text { Dempo }\end{array}$

Nama Perusahaan : PT.PELNI

Jenis Kapal : Passenger

Adapun pengamatan yang dilakukan adalah mengamati jalannya proses embarkasi dan debarkasi di setiap pelabuhan yang disinggahi dan mengamati proses pemeriksaan tiket di pelabuhan. Menurut macam atau jenisnya, data dibedakan menjadi dua, yaitu data primer dan data sekunder dengan menggunakan beberapa teknik pengumpulan data yang dianggap tepat yaitu metode observasi (pengamatan), metode wawancara, dan studi pustaka.

Metode penelitian yang digunakan adalah metode deskriptif dengan menggambarkan dan menguraikan tentang bagaimana cara mengatasi ketidaktertiban pedagang asongan dan buruh-buruh bagasi dalam pengangkutan barang milik penumpang sewaktu pelaksanaan embarkasi dan debarkasi terhadap keberangkatan kapal KM. Gunung Dempo.

Dengan metode deskriptif ini juga diselidiki kedudukan (status) fenomena atau faktor dan melihat hubungan antara satu faktor dengan faktor yang lain Karenanya, metode deskriptif juga dinamakan studi status (status study).

Dalam pembahasan dipaparkan tentang hasil yang telah didapat mengenai objek yang diteliti dan melakukan penelitian di lapangan, dengan cara mengamati secara langsung di kapal penumpang KM. Gunung Dempo.

Data yang diperoleh melalui wawancara dengan Mualim II KM. Gunung Dempo selaku penanggung jawab tiket penumpang dan Mualim I sebagai penanggung jawab proses embarkasi dan debarkasi di setiap pelabuhan yang disinggahi kapal.

Penelitian ini menggunakan lebih dari satu teknik analisis data. Berikut adalah teknik analisis data yang 
digunakan dalam penelitian yaitu sebagai berikut :

a. Reduksi data

Proses reduksi data penulis akan memilih hal-hal pokok, memfokuskan pada hal-hal yang penting dan membuang data yang tidak diperlukan. Dengan demikian data yang telah direduksi akan memberikan gambaran lebih jelas mengenai permasalahan penelitian ini.

b. Penyajian data

Penyajian data yang berupa sekumpulan informasi yang telah tersusun secara terpadu dan mudah dipahami yang memberikan kemungkinan adanya penarikan kesimpulan dan pengambilan tindakan.

c. Penarikan simpulan

Penarikan simpulan merupakan kemampuan seorang peneliti dalam menyimpulkan berbagai data yang diperoleh selama proses penelitian berlangsung.

\section{HASIL DAN PEMBAHASAN}

Pada kapal penumpang proses embarkasi dan debarkasi merupakan salah satu hal penting yang tidak bisa dipisahkan dalam perkembangannya dan merupakan hal pokok karena proses embarkasi dan debarkasi berkaitan dengan jadwal keberangkatan kapal. Untuk mencegah terjadinya keterlambatan keberangkatan kapal, maka pihak perusahaan Pelni memberikan jadwal keberangkatan kapal secara permanen agar bisa menjadi sebuah landasan bagi awak kapal, pihak cabang Pelni dan pihak pelabuhan dalam mengelola waktu agar dapat mengantisipasi dan mempersiapkan kedatangan kapal dengan matang dan segala kegiatan dapat berjalan dengan lancar, cepat, aman dan efisien.

Kenyataan yang terjadi di lapangan, bahwa kapal masih sering mengalami keterlambatan tiba di pelabuhanpelabuhan berikutnya. Kapal selalu berangkat dari pelabuhan pertama sesuai https://doi.org/10.46484/db.v1i1.178 dengan jadwal yang telah ditentukan dan biasanya tiba di pelabuhan berikutnya sesuai dengan jadwal yang ditentukan juga. Namun, setelah dua pelabuhan pertama, kapal sering mengalami keterlambatan menuju ke pelabuhan akhir hingga 5 jam. Hal ini dikarenakan proses embarkasi dan debarkasi yang tidak sesuai dengan jadwal.

Dari hasil penelitian yang dilakukan tentang pelaksanaan embarkasi dan debarkasi di setiap pelabuhan yang disinggahi dilakukan sebagai berikut :

a. Proses pelaksanaan embarkasi penumpang.

Dalam pelaksanaan embarkasi harus mengikuti prosedur pelaksanaan yang sudah ditetapkan. Adapun prosedur pelaksaan embarkasi penumpang adalah sebagai berikut:

1) Calon penumpang harus berada di daerah terminal penumpang kurang lebih setengah jam sebelum kapal berangkat.

2) Penumpang wanita dan anakanak diperbolehkan naik terlebih dahulu.

3) Calon penumpang naik tidak boleh memasuki daerah dekat kapal sandar sebelum jam keberangkatan kapal.

4) Penumpang hanya boleh naik jika tangga sudah terpasang dengan baik dan benar serta petugas telah ada dan dilarang naik lewat tangga pandu disebelah lambung kapal.

b. Proses pelaksanaan debarkasi penumpang

Sama halnya dengan embarkasi, proses debarkasi juga harus mengikuti prosedur yang sudah ditetapkan. Proses pelaksanaan debarkasi penumpang adalah sebagai berikut:

1) Penumpang harus menunggu sampai tangga terpasang dengan baik dan benar.

2) Penumpang wanita dan anakanak turun terlebih dahulu.

3) Penumpang dengan bawaan berat menunggu turun paling akhir. 
4) Penumpang yang akan melanjutkan perjalanan boleh turun dan beristirahat sebentar di terminal penumpang.

5) Penumpang yang baru saja turun dari kapal harus melalui pemeriksaaan petugas tentang barang bawaannya.

c. Pengamanan Jalannya Embarkasi dan Debarkasi Penumpang.

Berdasarkan hasil wawancara dengan Nakhoda KM. Gunung Dempo, pengamanan pada waktu pelaksanaan embarkasi dan debarkasi penumpang sangat diperlukan guna menciptakan kenyamanan dan kelancaran. Banyaknya penumpang yang akan naik turun serta maraknya pedagang asongan, buruh-buruh bagasi dan pengantar menjadi penyebab perlu ditingkatkan pengamanan embarkasi dan debarkasi penumpang.

Penumpang yang telah membeli tiket dan sebelum naik ke atas kapal terlebih dahulu menunggu di terminal penumpang. Penumpang yang akan memasuki terminal penumpang akan diperiksa oleh pihak pelabuhan dengan cara melaksanakan pengawasan tehadap kunjungan atau keberangkatan kapal dan arus penumpang kapal yang akan turun dan naik.

Tindakan kriminal masih sering terjadi di dalam terminal penumpang, misalnya pencopetan. Port Security selalu melakukan sweeping di dalam terminal penumpang untuk mencegah terjadinya tindakan kriminal tersebut para calon penumpang kapal yang berada di terminal penumpang merasa nyaman.

Penanganan yang dapat dilakukan untuk mengcegah adanya keterlambatan keberangkatan kapal KM. Gunung Dempo dengan meningkatkan kerja sama dan koordinasi dalam berbagai lini untuk menertibkan banyaknya jumlah https://doi.org/10.46484/db.v1i1.178 penumpang yang akan naik dan turun dari kapal. Karena banyaknya jumlah penumpang yang akan naik bersamaan dengan penumpang yang akan turun dan juga jadwal keberangkatan kapal yang tidak dapat ditunda maka harus diadakan penertiban baik dari pihak kapal itu sendiri maupun dari pihak pelabuhan dalam hal ini adalah KPLP / KPPP (Kesatuan Penjagaan Laut dan Pantai / Kesatuan Pelaksanaan Pengamanan Pelabuhan).

Salah satu cara untuk menertibkan penumpang yang akan naik dan turun dengan membagi jalur dimana tempat / tangga untuk penumpang naik dan tangga untuk penumpang turun. Selain itu, tangga pelabuhan dapat diberikan tanda dimana jalur yang dapat digunakan untuk naik dan untuk turun. Berdasarkan hasil wawancara dengan Nakhoda KM. Gunung Dempo, untuk masalah yang berdesak-desak, Mualim 1 telah bekerja sama dengan perwira deck lain dan di bantu oleh Satpam, Serang, Jenang dan beberapa pelayan untuk mengatur jalannya arus penumpang dan barang yang masuk dan keluar dari kapal. Penumpang wanita dan anak-anak diperbolehkan turun terlebih dahulu dan penumpang yang bawaannya berat harus turun dibelakang. Sedangkan dari pihak darat atau dermaga telah ada petugas yang berjaga dibawah tangga embarkasi dan debarkasi. Penumpang yang naik di atas kapal diperiksa barang dan tiketnya yang telah dibeli oleh petugas.

Dalam beberapa kasus di pebahuhan Indonesia bagian Timur, sering terjadi dimana kapal hanya menggunakan 1 (satu) tangga gangway yang digunakan untuk penumpang naik sekaligus turun. Hal ini justru menghambat jalannya proses embarkasi dan debarkasi karena ukuran tangga gangway yang terbatas akan mengakibatkan penumpang yang naik dan turun berdesak-desakan sehingga justru mengakibatkan kemacetan di tangga gangway, ditambah dengan buruh bagasi yang membawa barang-barang besar milik penumpang 
semakin menghambat jalan penumpang di tangga gangway.

Merebaknya pengantar dan pengunjung sewaktu pelaksanaan embarkasi dan debarkasi penumpang merupakan salah satu penyebab terhambatnya pelaksanaan embarkasi dan debarkasi penumpang. Pengantar seharusnya tidak boleh masuk ke dalam terminal penumpang, akan tetapi pengantar justru ikut masuk ke dalam terminal penumpang sehingga terminal penumpang menjadi penuh. Bahkan ada pengantar yang nekat mengantar hingga kedalam kapal. Sewaktu kapal akan segera berangkat atau bertolak dari pelabuhan, kapal akan melakukan pengumuman lewat pengeras suara yang berada di anjungan sebanyak tiga kali yakni satu jam, setengah jam, dan lima menit sebelum berangkat yang ditujukan kepada para pengantar, pengunjung dan buruh-buruh bagasi untuk segera turun dari kapal. Pengalaman sewaktu praktek prala di kapal KM. Gunung Dempo kejadian di pelabuhan Manokwari ada pengantar yang ikut dalam pelayaran yakni seorang wanita dan kejadian ini langsung di laporkan ke anjungan dan Nakhoda terpaksa menurunkannya lewat perahu nelayan dan tidak mungkin kembali ke dermaga.

Berdasarkan pengamatan penelitian di KM. Gunung Dempo, untuk menangani pengantar dan pengunjung kapal melakukan : 1) Pengantar dan pengunjung tidak boleh masuk ke dalam kapal jika tidak mendesak dan sewaktu embarkasi dan debarkasi dan tidak boleh mengganggu pelaksanaan embarkasi dan debarkasi; 2)Pengantar dan pengunjung tidak boleh berlama-lama di atas kapal ; 3) Pengantar pengunjung harus segera turun dari kapal jika kapal akan segera berangkat.

Upaya-upaya yang dilakukan untuk mengurangi terjadinya keterlambatan pemberangkatan kapal KM. Gunung Dempo :

a. Dermaga penumpang sebaiknya diberi pagar pembatas yang tinggi dan terbuat dari besi guna mencegah

https://doi.org/10.46484/db.v1i1.178 penumpang, buruh-buruh bagasi, pengantar, pengunjung, pedagang asongan dan orang-orang yang tidak berkepentingan yang akan mengganggu pelaksanaan embarkasi dan debarkasi

b. Melakukan pengecekan rutin terhadap mesin kapal agar tidak terjadi kerusakan pada saat perjalanan, selalu menanyakan dan mengecek keadaan cuaca di pelabuhan sandar selanjutnya.

c. Meningkatkan pelayanan dan fasilitas bagi penumpang. Ketidaksabaran penumpang disebabkan penumpang harus berdesakan dengan buruh-buruh bagasi, pengantar dan pengunjung dalam waktu sandar kapal yang terbatas. Ditambah dengan fasilitas kelas ekonomi yang tidak merata mengakibatkan penumpang berebut untuk masuk terlebih dahulu agar mendapatkan tempat yang nyaman.

d. Meningkatkan ketertiban dan kerjasama antara pihak kapal, pihak cabang dan pihak pelabuhan untuk menanggulangi buruh-buruh bagasi. Banyak buruh-buruh bagasi yang naik kapal secara tidak tertib menyebabkan proses embarkasi dan debarkasi penumpang terganggu dan dapat terjadi kemacetan di tangga untuk naik maupun tangga untuk turun. Berdasarkan pengalaman ketika kapal sudah mendekati pelabuhan para buruh bagasi sudah bersiap di dekat pelabuhan dan jumlah mereka sangatlah banyak, dan ketika kapal sudah sandar dan menurunkan tangga gangway para buruh bagasi langsung menyerbu kapal. Walaupun sudah ada penjagaan dari satpam namun tetap menerobos masuk. Cara mengatasi persoalan mengenai buruh bagasi adalah dengan cara melakukan kerjasama dari pihak kapal, cabang dan pelabuhan untuk menerapakan peraturan-peraturan berikut yang bisa menjadi opsi untuk menanggulangi buruh-buruh bagasi : 
1) Selain awak kapal dan penumpang yang memiliki tiket dilarang memasuki area pelabuhan.

2) Penumpang yang membawa barang bawaan yang banyak wajib dimuat di palka mengunakan crane. Selain itu untuk tercapainya peraturan tersebut dengan optimal pihak kapal, pihak cabang dan pihak pelabuhan harus selalu melakukan koordinasi dan menambah jumlah anggota keamanan.

3) Menambah jumlah personil untuk mengatasi jumlah penumpang yang banyak pihak kapal, pihak cabang dan pihak pelabuhan selalu melakukan kerjasama untuk menertibkan penumpang, selain itu untuk mengarahkan penumpang agar sesuai pada tempatnya maka jumlah personil harus ditambah baik di darat maupun diatas kapal selain itu hendaknya setiap petugas mengetahui tugasnya masing-masing dan pemerataan tugas kepada setiap petugas sehingga tercipta ketertiban mulai dari terminal tunggu penumpang hingga proses embarkasi dan debarkasi berjalan lancar dan kapal bisa bertolak dari pelabuhan sesuai dengan jadwal keberangkatan.

\section{SIMPULAN}

Keterlambatan pemberangkatan kapal KM. Gunung Dempo disebabkan antara lain tidak tertibnya penumpang, pengantar, buruh-buruh bagasi dan pedagangan asongan pada proses embarkasi dan debarkasi penumpang, cuaca ekstrim yang tidak menentu, dan terjadinya kerusakan pada mesin kapal.

Upaya yang bisa dilakukan untuk mengurangi keterlambatan pemberangkatan adalah dengan melakukan pengecekan rutin terhadap mesin kapal agar tidak terjadi kerusakan, https://doi.org/10.46484/db.v1i1.178 mengecek cuaca pada pelabuhan sandar selanjutnya, dan menambah petugas keamanan untuk menertibkan para penumpang, pengantar, dan pedagang asongan untuk menaati tata tertib yang ada, menambah fasilitas pelabuhan di dermaga penumpang, serta meningkatkan fasilitas dan pelayanan bagi penumpang.

Untuk meminimalisir keterlambatan kapal, sebaiknya PT. Pelayaran Nasional Indonesia (Pelni) beserta jajaranya melakukan pengecekan secara rutin terhadap mesin kapal agar tidak terjadi kerusakan pada saat perjalanan, selalu menanyakan dan mengecek keadaan cuaca di pelabuhan sandar selanjutnya, dan tidak memperbolehkan penumpang, pengantar, pengunjung, pedagang asongan, dan buruh-buruh bagasi untuk naik ke atas kapal.

Upaya mengatasi agar tidak terjadi keterlambatan kebengkatan kapal KM. Gunung Dempo diantaranya adalah: 1) meningkatkan fasilitas dan pelayanan bagi penumpang seperti hanya memperbolehkan penumpang yang sudah memiliki tiket dapat naik ke atas kapal dan dapat mencari tempat sesuai yang tertulis di tiket., selama proses embarkasi dan debarkasi berlangsung; 2) Petugas harus mengarahkan penumpang agar tidak memperbolehkan penumpang turun sebelum tangga embarkasi dan debarkasi terpasang dengan baik; dan 3) Penambahan fasilitas di dermaga seperti diberi pagar pembatas yang tinggi dan terbuat dari besi guna mencegah penumpang, buruh-buruh bagasi, pengantar, pengunjung, pedagang asongan dan orang-orang yang tidak berkepentingan yang akan mengganggu pelaksanaan embarkasi dan debarkasi.

\section{DAFTAR PUSTAKA}

Andiani, Dita. 2011. Terminal Feri Domestik Sekupang - Batam (Arsitektur Simbolis). Laporan Perancangan Tugas Akhir Departemen Arsitektur, Universitas Sumatera Utara. Diunduh dari 
http://repository.usu.ac.id/ handle/123456789/26972

Departemen Pendidikan Nasional RI., 2003. Konsep Dasar Perkapalan Mengenal Jenis-Jenis Kapal. Direktorat Jenderal Pendidikan Dasar Dan Menengah, Jakarta.

Haronjeff, Robert. 1993. Perencanaan dan Perancangan Bandar Udara. Erlangga. Jakarta

Morlok, Edward K. 1991. Pengantar Teknik dan Perencanaan Transportasi. Erlangga. Jakarta

Poerwardaminta W.J.S. 1993. Kamus Umum Bahasa Indonesia. P.N. Balai Pustaka. Jakarta

Sekretariat Negara Republik Indonesia. 2008. Undang-undang Nomor 17 tahun 2008 Tentang Kepelabuhan.
Lembaran Negara Republik Indonesia Tahun 2008, Nomor 127. Sekretariat Negara Republik Indonesia. Jakarta

Suyono. 2001. Kamus Besar Indonesia. Balai Pustaka. Jakarta

Triatmodjo, Bambang. 2008. Pelabuhan. Beta Offset. Yogyakarta

Wijoyono, Pius Honggo. 2012. Terminal Penumpang Kapal Laut Pelabuhan "Harbour bay" Pulau Batam. Program Studi Arsitektur Universitas Atma Jaya Yogyakarta. Yogyakarta

Website PT. Pelayaran Nasional Indonesia,

https://pelni.co.id/sejarah, Diakses pada 18 Mei 2019, pukul 10.42 